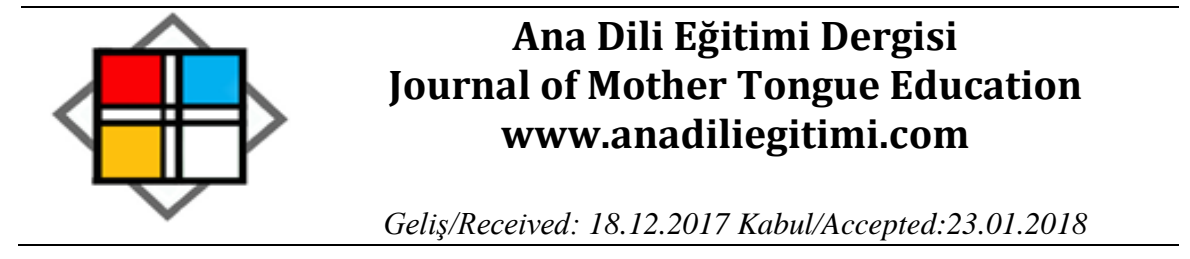

\title{
Ortaokul 8. Sınıf Öğrencilerinin Okur Özyeterlikleri ile Okuduklarını Anlama Becerileri Arasındaki ilişki*
}

Hatice ALTUNKAYA**

Öz

Çalışmada, ortaokul 8. sınıf öğrencilerinin okur özyeterlik algıları ile okuduklarını anlama becerileri arasındaki ilişki araştırılmıştır. Veri toplama araçları olarak Ülper, Yaylı ve Karakaya (2013) tarafından geliştirilmiş "Okur Özyeterlik Ölçeği” ve Dedebali ve Saracaloğlu (2010) tarafından geliştirilen "Okuduğunu Anlama Akademik Başarı Testi” kullanılmıştır. Söz konusu ölçek ve test Türkiye'nin batısında bir ilde ortaokul sekizinci sınıfta öğrenim gören 364 öğrenciye uygulanmıştır. Araştırma sonucunda, öğrencilerin okur özyeterlik algı düzeyi düşüklüğünün okuduğunu anlama düzeyini azalttığı tespit edilmiştir. Kızların özyeterlik algıları erkeklerden düşük olarak bulunan araştırmada, kızların okuduğunu anlama seviyelerinin erkeklerden yüksek olduğu tespit edilmiştir. Anne eğitim durumu ve aile aylık geliri değişkenlerine göre öğrencilerin özyeterlikleri ile okuduklarını anlama seviyeleri arasında anlamlı bir farklılık bulunmamıştır. Baba eğitim durumu değişkenine göre öğrencilerin okur özyeterliğinde anlamlı bir farklılık bulunmazken okuduğunu anlama üzerinde anlamlı bir farklılık bulunduğu, üniversite mezunu babaların çocuklarının okuduklarını anlama seviyelerinin daha yüksek olduğu ortaya konulmuştur.

Anahtar Kelimeler: Özyeterlik, okuma, okuduğunu anlama

\section{Correlation between the Reader Self-Efficacy Perceptions of $\mathbf{8}^{\text {th }}$ Grade Students and their Reading Comprehension Skills}

\begin{abstract}
In this study, the relationship between the reader self-efficacy perceptions of $8^{\text {th }}$ grade students and their reading comprehension skills was investigated. As data collection tools, the "Reader Self-Efficacy Scale" developed by Ülper, Yaylı and Karakaya (2013) and the "Reading Comprehension Academic Achievement Test" developed by Dedebali and Saracaloğlu (2010) were used. The scale and the test were administered to $3648^{\text {th }}$ grade students in a junior high school in a city in the western part of Turkey. The results of the study showed that low reader self-efficacy perceptions of the students decreased their reading comprehension levels. It was found that the self-efficacy perceptions of the female students were lower than those of the male students, and that the reading comprehension levels of the female students were higher than those of the male students. There was no significant difference between the self-efficacy beliefs of the students and their reading comprehension levels in terms of the education level of the mother and monthly family income variables. In terms of the variable education level of the father while there was no significant difference in the reader self-efficacy perceptions of the
\end{abstract}

\footnotetext{
* Bu çalışma 02-04 Kasım 2017 tarihleri arasında Malatya'da düzenlenen IX. Dünya Dili Türkçe Sempozyumu'nda sunulan bildirinin düzenlenmiş hâlidir.

** Yrd. Doç. Dr., Adnan Menderes Üniversitesi, Eğitim Fakültesi, Türkçe Eğitimi Bölümü. Aydın, Türkiye. eposta: hatice.altunkaya@adu.edu.tr
} 
students, there was a significant difference in the reading comprehension levels of the students whose fathers were university graduates.

Key Words: Self-efficacy, reading, reading comprehension

\section{Giriş}

\section{Özyeterlik İnancı ve Okur Özyeterliği}

Bireylerin karşılaştıkları bilişsel, duyuşsal ve davranışsal tepki gerektiren durumlarda, kendi kapasiteleri ile ilgili farkındalıkları özyeterlik algılarını oluşturur. Bireyin özyeterliğine ilişkin düşünceleri başarılı olup olmamada etken olan faktörlerdendir.

Özyeterlik inancı ilk kez 1977 yılında Bandura tarafından ortaya konulan ve devam eden yıllarda da (1986, 1989) davranışsal ve sosyal öğrenme kuramlarının bir çerçevesi olarak kullanılagelen; kişilerin sahip oldukları becerileri etkin şekilde kullanabilmeleri için önce ilgili alanda özgüven duymaları gerektiğini savunan "Sosyal Biliş Teorisi (Social Cognitive Theory)" adı verilen teorinin anahtar kavramıdır (Wood ve Bandura, 1989; Pajares, 2002).

Bandura (1986: 391) özyeterlik inancını "bireylerin belirli bir işi başarabilmek için gerekli eylemleri örgütleyebilme ve gerçekleştirebilme kabiliyetlerine ilişkin yargıları" olarak ifade eder. Bandura'ya göre (1997) özyeterlik algısının bireylerin düşünceleri, davranışları ve motivasyonları üzerinde doğrudan etkisi bulunmaktadır ve bireye "ben bu işi yapabilirim" hissini veren inançların kaynağını oluşturmaktadır. "Ancak bu durum, içi boş bir söylemden ziyade, bireyin yaşantıları yoluyla edindiği, sosyal ortamda olumlu geri bildirimlerle beslenen ve kendi çıkarımlarını içeren bir algıdır" (Bandura, 1997; Bandura, Barbaranelli, Caprara \& Pastorelli, 1996).

Bandura'nın da belirttiği gibi kişinin düşünceleri, davranışları ve motivasyonu üzerinde etkisi olan özyeterlik inancı, öğrenim sürecinde öğrencinin öğreneceği yeni bilgilere, karşılaşacağı yeni durumlara ilişkin davranışlarının belirleyicisi olacaktır. Özyeterlik inancı kuvvetli olan bir birey, karşılaştığı yeni durumlarda sebat ve ısrarla hareket ederek kaygı ve güven konusundaki hislerini düzenleyebilecek, kendi öğrenmesinden sorumlu olarak kendi güdülenmesini sağlayabilecektir. Özyeterlik inancı düşük bireyler için karşılaştıkları yeni durumlar, aşılması zor engeller gibi görünecektir ve bu düşüncelerine bağlı olarak bu bireyler, öğrenme sürecinde hedeflenen başarı düzeyini yakalayabilmek için gerekli olan içsel düzenlemeleri ve sahip oldukları koşulların düzenlemesini gerçekleştiremeyeceklerdir. "Koşulları düzenleyen, gözlem yapan, sonuçları tekrar değerlendirip çıkarımlar yapan bireyler, giriştikleri işte başarılı olma durumuna göre özyeterliklerini yapılandırmaktadırlar. Bireyin elde ettiği olumlu sonuçlar özyeterliğin yükselmesine, olumsuz sonuçlar ise özyeterliğin azalmasına yol açmaktadır” (Schunk, 2003: 160). 
Bandura (1986), özyeterlik yargılarının dört temel kaynaktan elde edilen bilgilerden etkilendiğini ortaya koymaktadır. Bu kaynaklar, doğrudan deneyimler, dolaylı yaşantılar, sözel ikna, duygusal durumdur.

Doğrudan deneyimler: Kişinin kendisinin başardığı işlerden elde ettiği deneyimlerdir. Insanlarda güçlü bir yeterlik inancının oluşumu, o kişinin doğrudan deneyimler yaşamasıyla olacaktır. Başarı, güçlü bir özyeterlik inancının oluşmasına neden olurken, başarısızlık bu inancı zedeleyecektir. Özellikle, güçlü bir özyeterlik inancı oluşmadan bir başarısızlık durumu yaşanırsa, birey büyük olasılıkla özyeterliğiyle ilgili olumsuz inançlar geliştirecektir. Doğrudan deneyimlerle oluşan özyeterlik inancı var olan bir alışkanlık gibi durumdan duruma transfer edilemez. Bu nedenle, değişen durumlara göre belirli eylemleri yapma ya da yönetmede bilişsel, davranışsal ve öz düzenleme becerilerinin önceden kazanılmış olması gerekmektedir.

Dolaylı yaşantılar: Sosyal modeller tarafından sağlanan dolaylı yaşantılar da yeterlik inançlarının oluşumunda ve güçlendirilmesinde etkili olan etmenlerden biridir. Model almanın özyeterlik inancına etkisi, model alınan kişinin algılanan benzerliklerinden güçlü bir şekilde etkilenmektedir. Birey, model aldığı kişinin kendisine oldukça çok benzediğini düşünüyorsa, modelin başarı ya da başarısızlığı onun için daha ikna edici olacaktır. İnsanlar, kendilerine benzer özelliklere sahip olduğunu düşündükleri bireylerin yaptıklarını görerek, izleyerek kendilerinin benzer bir durumda nasıl bir performans ortaya koyacakları konusunda bir yargıya ulaşırlar. Diğer taraftan, birey model aldığı kişinin kendisine çok da fazla benzemediğini düşünüyorsa, özyeterlik inancı modelin başarı ya da başarısızlığından çok da fazla etkilenmeyecektir.

Sözel ikna: Sözel ikna, özyeterlik inançlarını güçlendirmenin bir başka yoludur. Verilen işi tam olarak yapabilecek yeteneklere sahip olan ve bu yönde çevreden sözel mesajlar (örneğin; sen bu işi yaparsın, bu problemi çok rahat çözersin gibi) alan bireyler bir problemle karşılaştıklarında kuşkularını ve kişisel yetersizliklerini düşünmek yerine problemi çözmek için daha fazla çaba harcarlar ve bu çabayı sürdürme azmi gösterirler. Birey ikna edici bir teşvikle karşılaştığında, verilen görevi başarmak için zoru deneyecek ve deneyim başarılı olursa, bu bireysel doğrulama becerilerinin ve özyeterlik inançlarının gelişmesine katkı sağlayacaktır. Gerçekçi olmayan teşvikler ise, bireyin çabalarına karşın yaşayacağı başarısızık ve dolayısıyla hayal kırıklığı nedeniyle özyeterlik inancının hızlı bir şekilde azalmasına neden olacaktır.

Duygusal durum: Bireyin fiziksel ve duygusal durumu da yeteneklerine ilişkin yargılarının oluşumunda kısmen etkili olmaktadır. Bireyin ruhsal ve bedensel olarak kendini iyi hissetmesi, verilen bir görevi ya da istenilen bir davranışı yerine getirme olasılığını artıracaktır (Bandura 1986'dan akt. Akkoyunlu, Orhan ve Umay, 2005; Yavuzer ve Koç, 2002). 


\section{Okuma Becerisi ve Özyeterlik İnancı}

Okuma becerisi, ses bilgisi, seslem bilgisi, sözcük bilgisi, sözcük öbeklerini tanıma bilgisi, cümle bilgisi, dil bilgisel bağlantıları tanıma bilgisi, bağlaç bilgisi, cümle ögeleri arasındaki bağlantıları tanıma bilgisi gibi pek çok bilişsel bilginin yanısıra duyuşsal beceriler de gerektirmektedir. Wigfield, Guthrie, Tonks ve Prencevich (2004: 300) okuma özyeterliği, dil ve anlama becerilerine yönelik kendine güveni ifade ederken matematik özyeterliğinin sayısal becerilere ilişkin güveni ifade ettiğini, her dersin farklı nitelikte beceriler gerektirdiği için öğrencilerin bu becerilere yüklediği anlamın da farklılaştığını ifade etmektedirler.

Applegate ve Applegate (2004) birçok araştırma sonucuna dayanarak öğrencilerin bilişsel açıdan yeterli olmalarına karşın okumaya karşı isteksiz olduklarını yani okumayı yeğlemediklerini belirtmişlerdir.

Güdüsel süreçler içerisinde gösterilen özyeterlik inancı, metni kavrama yolunda okuma amacı, içsel güdü ve ilgi ile beraber okuma anlamlandırma becerisinin gereklerinden biri olarak dikkat çekmektedir. Wigfield ve Guthrie (1997) diğer inançlar arasında yeterlik inancının aktivite seçimini belirlemenin yanısıra kişinin ilgi duyduğu bir aktivite için çaba harcamada istekli olmasını da belirlediğini ifade etmişlerdir. Bilişsel- Güdüsel Okuma Modelinde Guthrie ve Wigfield (1999: 201), metni anlama sürecini etkileyen güdüsel süreçlerden biri olarak etkili okuma kapasitesine sahip olan okuyucu duygusu olarak okuyucunun özyeterlik inancının önemini özellikle vurgulamaktadırlar. Epçaçan ve Demirel de (2001:125) özyeterlik kavramının, öğrencilere öğretildiği zaman, öğrencilerde önemli bir etkiye sahip olan, öğrencilerin okuduğunu anlama becerilerinin önemli bir ölçüde gelişmesine katkı sağlayan dikkate değer bir değişken olarak kabul edilmesi gerektiğini belirtmişlerdir. Pek çok çalışmada, okuma özyeterlik algısı yüksek olan bireylerin okuduğunu anlama ve zor metinlerle mücadele etmede düşük özyeterlik sahibi okurlardan daha başarılı oldukları tespit edilmiştir (Guthrie ve Wigfield, 2000; Solheim, 2011; McQuillan, 2000 ).

Özyeterliği olan bir öğrenci okuyabileceğine inanır ve çevresindeki okuma metinlerine ilgi gösterir. Bu durum kişide içsel bir okuma isteği uyandırır ve kişi içsel isteklenme düzeyinin kendisinde yarattığı itkiye bağıı olarak okumaya yönelir. Bu yönelimle birlikte, bir metni okuma sürecine giren okur, metnin şematik yapısından yararlanarak, metnin uyaranlarının etkisiyle konuya ilişkin ön bilgilerini etkinleştirerek ve metindeki bilgiyle ön bilgilerini etkileştirerek metinden anlamsal çıkarımlar yapar (Ülper, 2011: 942).

Okuma özyeterliği yüksek olan bir öğrenci, okuma anlamlandırma sürecinde okuma amacını doğru bir şekilde belirleyerek kendisine hedef belirleyecektir. Bu hedefe ulaşabilmek için gerekli çaba, 
enerji, dikkat, azim gibi faktörlere ilişkin gücü özyeterlik inancından gelen kaynakla aşma gayretinde bulunacak ve başarısızlıklar karşısında yılmadan başarmak için uğraş verebilecektir.

Henk ve Melnick (1992) bireyin bir okuyucu olarak kendisi hakkında nasıl hissettiğinin, onun okuma sırasında ortaya koyacağı çabanın miktarını arttırıp arttırmayacağını ya da okumaktan kaçınmak isteyeceğini ve okuduğunu anlamada sebatını ne kadar ısrarla sürdürebildiğini açıkça etkilediğini ifade etmektedirler.

Kubanoğlu (2004), her türlü eğitim programı için değerlendirmede öğrenci veya katılımcıların bilgi düzeylerinin yanısıra özyeterlik düzeylerinin ölçümünü tavsiye etmektedir. Böylece eğitim programlarının sadece bilgi değil aynı zamanda deneyim kazandırma kapasitelerinin de değerlendirilmesinin söz konusu olabileceği belirtilmiştir.

Bireylerin okumaya ilişkin öz algılarını/yeterliklerini belirlemeye yönelik ölçme araçları Bandura'nın (1977) özyeterlik kavramı üzerinde şekillendirilmiştir (Epçaçan ve Demirel, 2011; Henk ve diğerleri, 2012; Henk ve Melnick, 1995; Ülper, Yaylı ve Karakaya, 2013; Keskin ve Atmaca, 2014). Türkçenin eğitimi öğretimi alanında yapılan çalışmalar incelendiğinde ortaokul sekizinci sınıf öğrencilerinin okur özyeterlik algı düzeyleri ile okuduğunu anlama düzeyleri arasındaki ilişkinin tespit edilmesine yönelik bir çalışma tespit edilememiştir. Okuduğunu anlama gibi tüm dersleri öğrenebilmenin temel anahtarı olan bir konu üzerine etkisi olabilecek faktörlerden özyeterlik algı düzeyi ile okuduğunu anlama ilişkisini araştırmanın gerekli olabileceği düşünülmüştür. Araştırmada kullanılan ölçeği geliştiren Ülper ve Karakaya (2013) “okuma sorunlarının saptanması sürecinde okumanın duyuşsal yanıyla ilgili olası sorunların saptanması ve sorunlara doğru tanımlamalar getirerek çözüm sürecine katkı sağlanması açısından" ölçekten yararlanılabileceğini ifade ederek bir bakıma yapılan çalışmaya da ışık tutmuşlardır.

Bu araştırmanın problem cümlesini “Ortaokul 8. sınıf öğrencilerinin okur özyeterlik algıları ile okuduklarını anlama becerileri arasındaki ilişki nasıldır?" sorusu oluşturmaktadır.

Alt problem cümleleri şu şekilde düzenlenmiştir:

1. 8. sınıf öğrencilerinin okur özyeterlik algıları ne düzeydedir?

2. 8. sınıf öğrencilerinin okur özyeterlik algıları, cinsiyete göre anlamlı bir farklııı göstermekte midir?

3. 8. sınıf öğrencilerinin okur özyeterlik algıları anne eğitim durumuna göre anlamlı bir farklılık göstermekte midir?

4. 8. sınıf öğrencilerinin okur özyeterlik algıları baba eğitim durumuna göre anlamlı bir farklılık göstermekte midir? 
5. 8. sınıf öğrencilerinin okur özyeterlik algıları ailenin ortalama aylık gelir düzeyine göre anlamlı bir farklılık göstermekte midir?

6. 8. sınıf öğrencilerinin okuduklarını anlama düzeyleri nasıldır?

7. 8. sınıf öğrencilerinin okuduklarını anlama düzeyleri cinsiyete göre anlamlı bir farklııı göstermekte midir?

8. 8. sınıf öğrencilerinin okuduklarını anlama düzeyleri anne eğitim durumuna göre anlamlı bir farklılık göstermekte midir?

9. 8. sınıf öğrencilerinin okuduklarını anlama düzeyleri baba eğitim durumuna göre anlamlı bir farklılık göstermekte midir?

10. 8. sınıf öğrencilerinin okuduklarını anlama düzeyleri ailenin ortalama aylık gelir düzeyine göre anlamlı bir farklılık göstermekte midir?

\section{Yöntem}

\section{Araştırma Modeli}

Bu araştırma, "geçmişte ya da hâlen var olan bir durumu var olduğu şekliyle betimlemeyi amaçlayan tarama modeli kapsamında, karşılaştırma ve korelasyon türünden tarama yapmaya imkân tanıyan ilişkisel tarama modelinde (Karasar, 2002) gerçekleştirilmiştir.

\section{Çalışma Grubu}

Araştırmanın çalışma grubunu, Türkiye'nin batısında yer alan bir ilin merkez ilçesinde bulunan 5 ortaokulda öğrenim gören 364 öğrenci oluşturmuştur. Ölçek ve başarı testleri 500 öğrenciye uygulanmıştır. Eksik ya da yanlış doldurulan formlar elendikten sonra geriye kalan 364 öğrenciye ait veriler araştırmada kullanılmıştır.

Tablo 1. Öğrencilerin Tanımlayıcı Özelliklerinin Dağı̆ımı

\begin{tabular}{llll}
\hline Tablolar & Gruplar & Frekans(n) & Yüzde (\%) \\
\hline Cinsiyet & Kız & 195 & 53,6 \\
& Erkek & 169 & 46,4 \\
& Toplam & 364 & 100,0 \\
Anne Eğitim Durumu & Ilkokul Mezunu & 32,1 \\
& Ortaokul Mezunu & 117 & 13,7 \\
& Lise Mezunu & 50 & 31,9 \\
& Üniversite Mezunu & 116 & 22,3 \\
Baba Eğitim Durumu & Toplam & 81 & 100,0 \\
& Ilkokul Mezunu & 364 & 22,3 \\
& Ortaokul Mezunu & 81 & 14,6 \\
& Lise Mezunu & 53 & 30,8 \\
& Üniversite Mezunu & 112 & 32,4 \\
& Toplam & 118 & 100,0 \\
\hline
\end{tabular}


Ortaokul 8. Sınıf Öğrencilerinin Okur Özyeterlikleri ile Okuduklarını Anlama Becerileri Arasındaki İlişki

\begin{tabular}{cccc}
\hline Aile Aylık Geliri & $1000-2000$ & 76 & 20,9 \\
& $2001-3000$ & 96 & 26,4 \\
& $3001-4000$ & 85 & 23,4 \\
& $4001-5000$ & 47 & 12,9 \\
& 5000 üzeri & 60 & 16,5 \\
& Toplam & 364 & 100,0 \\
\hline Öğrenciler cinsiyet değişkenine göre 195 'i $(\% 53,6) \quad$ kız, 169'u $(\% 46,4)$ erkek olarak \\
dağılmaktadır.
\end{tabular}

Öğrenciler anne eğitim durumu değişkenine göre 117'si $(\% 32,1)$ ilkokul mezunu, 50'si $(\% 13,7)$ ortaokul mezunu, 116 'sı $(\% 31,9)$ lise mezunu, 81'i $(\% 22,3)$ üniversite mezunu olarak dağılmaktadır.

Öğrenciler baba eğitim durumu değişkenine göre 81'i (\%22,3) ilkokul mezunu, 53'ü $(\% 14,6)$ ortaokul mezunu, 112'si $(\% 30,8)$ lise mezunu, 118'i $(\% 32,4)$ üniversite mezunu olarak dağılmaktadır.

Öğrenciler aile aylık geliri değişkenine göre 76'sı (\%20,9) 1000-2000, 96'sı (\%26,4) 2001-3000, 85 'i (\%23,4) 3001-4000, 47'si (\%12,9) 4001-5000, 60'ı (\%16,5) 5000 üzeri olarak dağılmaktadır.

\section{Veri Toplama Araçları}

Çalışmada, geçerliği ve güvenirliği önceden saptanmış, Ülper, Yaylı ve Karakaya (2013) tarafından geliştirilmiş "Okur Özyeterlik Ölçeği” ve Dedebali ve Saracaloğlu (2010) tarafından geliştirilen ve geçerlik-güvenirlik çalışmaları yapılan "Okuduğunu Anlama Akademik Başarı Testleri” kullanılmıştır. Okuduğunu anlama testlerinin güvenirliği için, "iç tutarlılık (internal consistency)" ölçütlerinden "Bir Testin íkiye Bölünmesi Yöntemi” kullanılmıştır (Tekin, 1994: 60-61). Bu yönteme uygun olarak, okuduğunu anlama testlerindeki sorular tek ve çift numaralı sorular olarak iki eşit yarıya bölünmüş ve 120 öğrencinin testlerin iki yarısından aldıkları puanlar arasındaki ilişki (korelasyon katsayısı) bulunmuştur. Bu işlem sonrasında, gazete haberi metnine ait testin güvenirliği $r=0.73$; bilimsel metne ait testin güvenirliği $r=0.70$; edebî metne ait testin güvenirliği $r=0.75$ olarak bulunmuştur. Bu değerler, okuduğunu anlama testlerinin güvenirliği için yeterli bir kanıt olarak görülmüştür (Dedebali ve Saracaloğlu, 2010). Bu araştırmada özyeterlik ölçeğinin güvenirliği Cronbach's Alpha=0,922 olarak yüksek bulunmuştur. Okuduğunu anlama testlerinin güvenirlik değerleri KR21=0,860; KR20=0,874 şeklinde yüksek olarak tespit edilmiştir.

\section{Verilerin Analizi}

Araştırmada elde edilen nicel veriler SPSS 22 programı ile analiz edilmiş ve veriler değerlendirilirken tanımlayıcı istatistiksel yöntemler olan sayı, yüzde, ortalama, standart sapma tanımsal olarak ifade edilmiştir. İki bağımsız grup arasında nicel olan sürekli verilerin karşılaştırılmasında t-testi, ikiden fazla bağımsız grup arasında nicel sürekli verilerin karşılaştırılmasında tek yönlü Anova testinden yararlanılmıştır. Daha sonra farklılıkları ortaya koymak üzere tamamlayıcı post-hoc analizi olarak Scheffe testi kullanılmıştır. Araştırmanın sürekli 
değişkenleri arasında pearson korelasyon ve regresyon analizi uygulanarak elde edilen sonuçlar \%95 güven aralığında, \%5 anlamlııı düzeyinde değerlendirilmiştir.

\section{Bulgular}

Çalışmanın "Ortaokul 8. sınıf öğrencilerinin okur özyeterlik algıları ile okuduklarını anlama becerileri arasındaki ilişki nasıldır?" temel problemine ilişkin bulgular Tablo 2'de sunulmuştur:

Tablo 2. Okur Özyeterlik Algısı ile Okuduğunu Anlama Düzeyi Arasındaki Korelasyon Iliş̧kisi

\begin{tabular}{lll}
\hline & Özyeterlik \\
\hline Okuduğunu Anlama & $r$ & $-0,234^{* *}$ \\
& $p$ & 0,000 \\
\hline
\end{tabular}

$*<0,05 ; * *<0,01$

Okuduğunu anlama ve okur özyeterlik algısı arasında çok zayıf, negatif yönde anlamlı ilişki bulunmaktadır $(r=-0.234 ; p=0,000<0.05)$.

Tablo 3. Okur Özyeterlik Algısının Okuduğunu Anlama Üzerine Etkisi

\begin{tabular}{llllllll}
\hline Bağımlı Değişken & Bağımsız Değişken & $\mathbf{B}$ & $\mathbf{t}$ & $\mathbf{p}$ & $\mathbf{F}$ & Model (p) & $\mathbf{R}^{\mathbf{2}}$ \\
\hline \multirow{2}{*}{ Okuduğunu Anlama } & Sabit & 91,438 & 21,810 & 0,000 & 20,936 & 0,000 & 0,052 \\
& Özyeterlik & $-9,920$ & $-4,576$ & 0,000 & & & \\
\hline
\end{tabular}

Okur özyeterlik algısı ile okuduğunu anlama arasındaki neden sonuç ilişkisini belirlemek üzere yapılan regresyon analizi istatistiksel olarak anlamlı bulunmuştur $(F=20,936 ; p=0,000<0.05)$. Okuduğunu anlama düzeyinin belirleyicisi olarak özyeterlik değişkenleri ile ilişkisinin (açıklayıcılık gücünün) zayıf olduğu görülmüştür $\left(R^{2}=0,052\right)$. Öğrencilerin okur özyeterlik algı düzeyi düşüklüğü, okuduğunu anlama düzeyini azaltmaktadır $(\beta=-9,920)$.

Araştırmanın birinci ve altıncı alt problemlerinde belirlenen 8. sınıf öğrencilerinin okur özyeterlik algı düzeyleri ile okuduklarını anlama düzeylerini belirlemeye yönelik gerçekleştirilen analizlerin sonucu Tablo 4'te aşağıda yer almaktadır:

Tablo 4. Öğrencilerin Okur Özyeterlik ve Okuduğunu Anlama Düzeyleri

\begin{tabular}{llllll}
\hline & $\mathbf{N}$ & Ort & Ss & Min. & Max. \\
\cline { 2 - 6 } Okur Özyeterlik Algısı & 364 & 1,877 & 0,467 & 1,000 & 3,810 \\
Okuduğunu Anlama & 364 & 72,821 & 19,806 & 20,000 & 100,000 \\
\hline
\end{tabular}

Araştırmaya katılan öğrencilerin "özyeterlik" puan ortalaması $(1,877 \pm 0,467)$; "okuduğunu anlama" puan ortalaması $(72,821 \pm 19,806)$; olarak saptanmıştır.

Araştırmanın alt problemlerinde belirlenen $2,3,4,5,7,8,9$ ve 10. problemlere ilişkin bulguların tümü tek tablo olarak Tablo 5 'te aşağıda verilmiştir: 
Ortaokul 8. Sınıf Öğrencilerinin Okur Özyeterlikleri ile Okuduklarını Anlama Becerileri Arasındaki iliş̧ki

Tablo 5. Öğrencilerin Okur Özyeterlik Algıları ve Okuduğunu Anlama Düzeylerinin Tanımlayıcı Özelliklere Göre Dağılımı

\begin{tabular}{|c|c|c|c|}
\hline Demografik Özellikler & $\mathbf{n}$ & Özyeterlik & Okuduğunu Anlama \\
\hline Cinsiyet & & Ort $\pm S S$ & Ort \pm SS \\
\hline $\mathrm{K} \mathrm{Iz}$ & 195 & $1,832 \pm 0,461$ & $76,256 \pm 18,487$ \\
\hline Erkek & 169 & $1,929 \pm 0,470$ & $68,856 \pm 20,577$ \\
\hline$t=$ & & $-1,989$ & 3,614 \\
\hline$p=$ & & 0,047 & 0,000 \\
\hline Anne Eğitim Durumu & & Ort $\pm S S$ & Ort $\pm S S$ \\
\hline İlkokul mezunu & 117 & $1,922 \pm 0,502$ & $69,601 \pm 20,992$ \\
\hline Ortaokul mezunu & 50 & $1,889 \pm 0,466$ & $70,933 \pm 19,738$ \\
\hline Lise mezunu & 116 & $1,882 \pm 0,434$ & $74,339 \pm 18,563$ \\
\hline Üniversite mezunu & 81 & $1,797 \pm 0,459$ & $76,461 \pm 19,310$ \\
\hline $\mathrm{F}=$ & & 1,167 & 2,347 \\
\hline$p=$ & & 0,322 & 0,072 \\
\hline Baba Eğitim Durumu & & Ort \pm SS & Ort \pm SS \\
\hline İlkokul mezunu & 81 & $1,971 \pm 0,504$ & $69,630 \pm 18,212$ \\
\hline Ortaokul mezunu & 53 & $1,937 \pm 0,456$ & $68,554 \pm 20,491$ \\
\hline Lise mezunu & 112 & $1,835 \pm 0,449$ & $71,012 \pm 20,620$ \\
\hline Üniversite mezunu & 118 & $1,825 \pm 0,454$ & $78,644 \pm 18,645$ \\
\hline $\mathrm{F}=$ & & 2,213 & 5,424 \\
\hline$p=$ & & 0,086 & 0,001 \\
\hline İleri Test (Tukey)= & & & $4>1,4>2,4>3(p<0.05)$ \\
\hline Aile Aylık Geliri & & Ort $\pm S S$ & Ort \pm SS \\
\hline $1000-2000$ & 76 & $1,912 \pm 0,527$ & $68,026 \pm 20,186$ \\
\hline $2001-3000$ & 96 & $1,947 \pm 0,444$ & $73,194 \pm 19,870$ \\
\hline $3001-4000$ & 85 & $1,879 \pm 0,419$ & $72,471 \pm 18,273$ \\
\hline 4001-5000 & 47 & $1,751 \pm 0,377$ & $75,674 \pm 21,724$ \\
\hline 5000 üzeri & 60 & $1,816 \pm 0,533$ & $76,556 \pm 19,124$ \\
\hline $\mathrm{F}=$ & & 1,780 & 1,925 \\
\hline$p=$ & & 0,132 & 0,106 \\
\hline
\end{tabular}

Araştırmanın değişkenleri olan cinsiyet, anne-baba eğitim durumu ve aile aylık gelir düzeyi doğrultusunda öğrencilerin okur özyeterlik algı düzeyleri ve okuduğunu anlama seviyelerinin değişip değişmediği araştırılmıştır. Bu araştırmalar neticesinde elde edilen bulgular değişkenlerin başlık olarak alınması suretiyle sunulmuştur:

Cinsiyet

Araştırmaya katılan öğrencilerin okur özyeterlik algı puanları ortalamalarının cinsiyet değişkeni açısından anlamlı bir farklılık gösterip göstermediğini belirlemek amacıyla yapılan T-Testi sonuçlarına göre, grup ortalamaları arasındaki fark anlamlı bulunmuştur ( $t=-1,989 ; p=0.047<0.05)$. Kızların okur özyeterlik algı puanları $(x=1,832)$, erkeklerin okur özyeterlik puanlarından $(x=1,929)$ düşük bulunmuştur.

Çalışmada yer alan öğrencilerin okuduğunu anlama puanları ortalamalarının cinsiyet değişkeni açısından anlamlı bir farklııı gösterip göstermediğini belirlemek amacıyla yapılan T-Testi 
sonuçlarına göre; grup ortalamaları arasındaki fark anlamlı bulunmuştur ( $t=3,614 ; p=0<0.05)$. Kızların okuduğunu anlama puanları $(x=76,256)$, erkeklerin okuduğunu anlama puanlarından $(x=68,856)$ yüksek bulunmuştur.

Anne eğitim durumu

Araştırmaya katılan öğrencilerin okur özyeterlik algı ve okuduğunu anlama puanları ortalamalarının anne eğitim durumu değişkeni açısından anlamlı bir farklılık gösterip göstermediğini belirlemek amacıyla yapılan test sonuçlarına göre grup ortalamaları arasındaki fark anlamlı bulunmamıştır $(p>0.05)$.

\section{Baba Eğitim Durumu}

Araştırmaya katılan öğrencilerin okur özyeterlik algı puanları ortalamalarının baba eğitim durumu değişkeni açısından anlamlı bir farklılık gösterip göstermediğini belirlemek amacıyla yapılan test sonuçlarına göre grup ortalamaları arasındaki fark anlamlı bulunmamıştır ( $p>0.05)$.

Öğrencilerin okuduğunu anlama puanları ortalamalarının baba eğitim durumu değişkeni açısından anlamlı bir farklılık gösterip göstermediğini belirlemek amacıyla yapılan tek yönlü varyans analizi (Anova) sonuçlarına göre; grup ortalamaları arasındaki fark anlamlı bulunmuştur ( $F=5,424$; $\mathrm{p}=0.001<0.05$ ). Farklılı̆ın hangi gruptan kaynaklandığını belirlemek üzere Post-Hoc testi uygulanmıştır. Buna göre; baba eğitim durumu üniversite mezunu olanların okuduğunu anlama puanları $(78,644 \pm 18,645)$, baba eğitim durumu ilkokul mezunu olanların okuduğunu anlama puanlarından $(69,630 \pm 18,212)$ yüksek bulunmuştur. Baba eğitim durumu üniversite mezunu olanların okuduğunu anlama puanları $(78,644 \pm 18,645)$, baba eğitim durumu ortaokul mezunu olanların okuduğunu anlama puanlarından $(68,554 \pm 20,491)$ yüksek bulunmuştur. Baba eğitim durumu üniversite mezunu olanların okuduğunu anlama puanları $(78,644 \pm 18,645)$, baba eğitim durumu lise mezunu olanların okuduğunu anlama puanlarından $(71,012 \pm 20,620)$ yüksek bulunmuştur.

\section{Aile Aylık Geliri}

Öğrencilerin okur özyeterlik algıları ve okuduğunu anlama puanları ortalamalarının aile aylık geliri değişkeni açısından anlamlı bir farklılık gösterip göstermediğini belirlemek amacıyla yapılan test sonuçlarına göre grup ortalamaları arasındaki fark anlamlı bulunmamıştır ( $p>0.05)$.

\section{Sonuç ve Tartışma}

İnsan davranışlarını etkileyen, bireylerin bir görev karşısında o görevi yapıp yapamayacaklarına dair kendileri hakkındaki yargılarını oluşturan özyeterlik inancı başarı üzerinde etkisi olan faktörlerdendir. Kavram olarak ilk kez Bandura tarafından ortaya konulan özyeterlik konusu çerçevesinde çok çeşitli araştırmalar gerçekleştirilmiştir. Bu araştırmalarda, okuma ve yazma 
sürecinde, özyeterlik inancı yüksek olan öğrencilerin bu becerileri başarılı bir şekilde edinebildikleri tespit edilmiştir (Philips, 2002; Schunk, 2003; Walker, 2003; Pajares, 2003; Bailey, 2009; Demir, 2013; Kwan ve Linderholm, 2014; Erdem, Altunkaya ve Ateş, 2017).

Araştırmada, sekizinci sınıf öğrencilerinin okur özyeterlikleri ile okuduklarını anlama becerileri arasındaki ilişki tespit edilmiştir. Okuduğunu anlama düzeyinin belirleyicisi olarak özyeterlik algı düzeyi düşüklüğünün okuduğunu anlama düzeyini azalttığı tespit edilmiştir. Demir (2013) 8. sınıf öğrencilerinin yaratıcı yazma becerileri ile yazma özyeterlik algıları arasındaki ilişkiyi incelemiş ve yazma özyeterliği yüksek olan öğrencilerin genellikle yaratıcı yazma becerilerinin de iyi düzeyde olduğunu tespit etmiştir. Solheim (2011) beşinci sınıf öğrencilerine yönelik yaptığı araştırmasında özyeterliğin okuduğunu anlama puanlarını olumlu yönde etkilediğini tespit etmiştir. Carroll ve Fox (2017) 8-11 yaş arasındaki öğrencilerde özyeterlik, kelime okuma ve okuduğunu anlama arasındaki ilişkiyi araştırmış ve sonucunda okuma özyeterliğinin kelime okuma ile ilişkisi bulunduğunu ancak okuduğunu anlama ile ilişkisi bulunmadığını tespit etmişlerdir. Conway (2017) lise öğrencilerine yönelik gerçekleştirdiği araştırmasında alt boyutları ilerleme, gözlemsel karşılaştırma, sosyal geri bildirim ve psikolojik durumlar olan Henk ve Melnick, (1995) tarafından geliştirilen okuma özyeterlik ölçeğini kullanmış ve araştırma sonucunda okuma özyeterliği ile okuduğunu anlama arasında orta düzeyde bir korelasyon olduğunu tespit etmiştir.

Çalışmada, sekizinci sınıf öğrencilerinin okur özyeterlik algı düzeylerinin 1,877 ortalama puan ile düşük düzeyde olduğu tespit edilmiştir. Baştuğ ve Çelik (2015) benzer şekilde "Ortaokul öğrencilerinin okur öz algı düzeylerinin cinsiyet, sınıf, okuma ortamı ve sıklığı açısından incelenmesi" adlı çalışmalarında öğrencilerin okur öz algılarının ölçeğin ilerleme boyutunda orta üzeri; gözlemsel karşılaştırma boyutunda orta, sosyal geri dönüt boyutunda ve fizyolojik durum boyutunda düşük düzeyde olduğunu tespit etmişlerdir. Araştırma bulguları ile aynı yönde olmayan çeşitli çalışmalar literatür taramasında dikkat çekmektedir. Uçgun (2014) "8. sınıf öğrencilerinin okur özyeterliklerinin incelenmesi: Niğde ili örneği” başlıklı çalışmasında öğrencilerin okur özyeterliklerinin yüksek düzeyde olduğunu tespit etmiştir. İnnalı ve Aydın da (2014) “ilköğretim 8. sınıf öğrencilerinin okur özyeterliklerinin çeşitli değişkenlere göre incelenmesi" adlı çalışmalarında öğrencilerin okur özyeterliklerinin yüksek düzeyde olduğunu tespit etmişlerdir. Öğrencilerin okur özyeterlik düzeylerinin farklı çıkma durumunun çalışmanın yapıldığı bölgenin koşulları, öğretmen durumu gibi etkenlere bağlanabileceği düşünülmektedir.

Öğrencilerin okuduklarını anlama puanları 72,821 şeklinde ortalamanın biraz üzerinde bulunmuştur. 
Öğrencilerin okur özyeterlik algı puanları ortalamaları cinsiyet değişkenine göre araştırılmış ve neticesinde kızların okur özyeterlik algı puanları erkeklerin okur özyeterlik algı puanlarından düşük bulunmuştur. Çeşitli araştırmalarda (Baker ve Wigfield, 1999; İnnalı ve Aydın, 2014; Uçgun, 2014; Baştuğ ve Çelik 2015) araştırma bulgularının aksi yönünde kızların okur özyeterlik algı puanlarının erkeklerden yüksek olduğu tespit edilmiştir. Karakoç Öztürk (2015) tarafından yapılan araştırma neticesinde ise öğrencilerin okur özyeterliklerinin farklılaşmadığı ortaya konulmuştur. Cinsiyet değişkenine göre okur özyeterlik algılarının araştırmalar arasında farklı sonuçlarda çıkma durumu, daha ileri boyutta yapılacak araştırmaları gerektirebilir.

Cinsiyet değişkenine göre öğrencilerin okuduklarını anlama seviyeleri sonuçları, kızların erkeklere göre okuduklarını anlamada daha başarılı olduklarını ortaya koymuştur. Okuma becerisi ile ilgili makalelerde cinsiyet değişkenini araştıran Arslan (2013), okuma becerisinin okuduğunu anlama gibi çeşitli yönlerinde cinsiyetler arasında bayanlar lehine olan birtakım sonuçlarının olduğunu, cinsiyet değişkeni ile ilgili farklılıklara ulaşan birçok makalenin bayanlar veya erkekler lehine olan durumun sebebini açıkla(ya)madığını ifade etmektedir. "Araştırmacılar bu sonucun, okumanın daha feminen bir uğraş olmasından, kızların okumada matematik ve fen bilimleri gibi alanlardan daha iyi olduklarının düşünülmesinden kaynaklandığını varsaymaktadır” (Piercey, 2013'ten akt. Karakoç Öztürk, 2015). Farklı çalışmalarda çıkan sonuçlar da (Gündemir, 2002; Sallabaş, 2008; Karatay, 2010; Köseoğlu, 2011; Ünal, 2012; Altunkaya, 2017) araştırma sonuçlarıyla tutarlı şekilde kız öğrencilerin daha başarılı olduğunu ortaya koymaktadır. Araştırma bulgularını desteklemeyen bir çalışmada yaygın bulgulardan farklı şekilde Kuşdemir ve Katrancı (2016) ilkokul dördüncü sınıf öğrencilerinin okuduğunu anlama ve ana fikir bulma becerileri ile okuma kaygıları arasındaki ilişkiyi inceledikleri çalışmalarında öğrencilerin okuduğunu anlama puanlarının cinsiyete göre anlamlı farklıık göstermediğini tespit etmişlerdir.

Araştırmada, öğrencilerin okur özyeterlik algıları ve okuduğunu anlama puanları ortalamalarının anne eğitim durumu açısından anlamlı farklılık göstermediği bulunmuştur. Çalışmada baba eğitim durumu değişkenine göre gerçekleştirilen analizler neticesinde okur özyeterlik algı puanları ortalamalarında bir farklılık bulunmazken okuduğunu anlama puanları arasında anlamlı farklılık ortaya çıkmıştır. Baba eğitim durumu üniversite olan öğrencilerin okuduğunu anlama puanları baba eğitim durumları ilkokul, ortaokul ve lise mezunu olanlardan yüksek olarak tespit edilmiştir. Kuşdemir ve Katrancı (2016) öğrencilerin anne ve baba öğrenim düzeyi ilkokuldan üniversiteye doğru ilerledikçe okuduğunu anlama puanlarının daha yüksek olduğunu tespit etmişlerdir. Altunkaya (2017) beşinci sınıf öğrencilerine yönelik yaptığı çalışmasında anne eğitim durumu ilkokul ve lise olanların başarı puanlarının anne eğitim durumu "okuryazar değil" olanların başarı puanlarından yüksek bulunduğunu, öğrencilerin baba eğitim durumu ilkokul ve lise olanların 
başarı puanlarının "okuryazar değil" olanların başarı puanlarından; lise olanların başarı puanlarının da üniversite olanların başarı puanlarından yüksek olduğunu ifade etmiştir.

Aile aylık geliri değişkeni doğrultusunda öğrencilerin okur özyeterlik algıları ve okuduğunu anlama puanları arasında anlamlı bir farklılık olmadığı tespit edilmiştir. Altun ve Yazıcı (2011) "Ergenlerin benlik algılarının yordayıcıları olarak akademik öz-yeterlik inancı ve akademik başarı" başıklı çalışmalarında üstün zekalı öğrencilerin sosyoekonomik durumları ile akademik özyeterlikleri arasında anlamlı bir farklııık bulunmadığını ifade etmiştir. Bircan ve Uzuner Yurt (2016) ortaokul öğrencilerinin okuma tutumları ile okuduğunu anlama özyeterlikleri arasındaki ilişkiyi araştırmışlar ve öğrencilerin ekonomik durumları zayıfladıkça özyeterlik algılarının da düştüğünü belirlemişlerdir. Altunkaya (2017) tarafından gerçekleştirilen araştırmada, ilkokul beşinci sınıf öğrencilerinin okuduğunu anlama başarı puanları ortalamalarının aile aylık geliri değişkeni açısından anlamlı bir farklılık gösterdiği sonucuna ulaşılmıştır. Aile aylık geliri 1001-2000; 2001-3000 TL arası ve 3000 Türk Lirasından fazla olanların başarı puanları, aile aylık geliri 500 Türk Lirasından az olanların başarı puanlarından yüksek bulunmuştur. Aile aylık geliri 1001-2000 TL arası olanların başarı puanları aile aylık geliri 5001-10000 TL arası olanların başarı puanlarından; aile aylık geliri 2001-3000 TL olanların başarı puanları 5001-10000 TL arası olanların başarı puanlarından yüksek bulunmuştur.

\section{Öneriler}

Wigfield ve Guthrie (1997) okuma özyeterliği ile okuma miktarı arasında pozitif yönlü orta düzeyde bir ilişki bulunduğunu belirlemiştir. Öğrencilerin okur özyeterlik algılarının ve okuduklarını anlama başarılarının yükseltilmesi, kitap okuma miktarları ile yakından ilgilidir. Millî Eğitim Bakanlığı, okul müdürleri, öğretmenler ve aileler öğrencileri daha çok okumaya yönlendirmek için çok çeşitli projeler gerçekleştirmelidir.

Öğretim programlarında okumanın duyuşsal boyutunda yer alan özyeterlik algısı kavramına yönelik de etkinlikler, yönergeler konulmalı, bilişsel yönden öğrencinin yeterli olsa bile duyuşsal yönden yeterli değilse tam anlamıyla başarılı olamayacağı göz önünde bulundurulmalıdır.

Öğretmenler öğrencilerini, okur özyeterlik algılarının artırılması için başarılı deneyimler gerçekleştirebilecekleri şekilde yönlendirmeli, sınıf ortamında öğrencilerin dolaylı yaşantılar yoluyla birbirlerinin özyeterlik algılarını yükseltecek şekilde ilişkiler kurabilmelerine aracılık etmelidir. Hem öğretmenler hem de aileler öğrencilerin okur özyeterlik algılarının yükseltilebilmesi ve böylece de okuduğunu anlamada başarılı olabilmeleri için sözel iknayı olması gerektiği şekilde uygulamalıdır.

Özyeterlik algısının kaynaklarından olan psikolojik durum da öğrencilerin algılarını etkilemektedir. Bu nedenle eğitim ortamlarının öğrenci psikolojisine uygun şekilde düzenlenmesinin yararlı olacağı düşünülmektedir. 
Aileler, çocuklarının okur özyeterlik algılarını yükseltmek için sözel iknada bulunmalı, onların kendilerine olan güvenini yükselterek başarılarına katkıda bulunmalıdır. Fan ve Williams (2010) ailenin yönlendirmelerinin öğrencilerin İngilizcede akademik özyeterlikleri ve içsel motivasyonlarını pozitif olarak etkilediğini tespit etmişlerdir. Özyeterliğin kaynakları arasında bulunan sözel ikna, özyeterliğin artırılmasında etkili olan faktörlerdendir.

OECD’nin 3 yılda bir yayınladığı ve ülkelerin eğitim sistemlerini ölçtüğü Uluslararası Öğrenci Değerlendirme Raporu'na (PISA 2016) göre Türkiye'nin, 64 ülke arasında 45. sırada yer alarak yine OECD ülkelerinin gerisinde kaldığı, okuduğunu anlama da $37^{\prime} n c i$ olduğu verileri daima dikkate alınmalı ve öğrencilerin okuduğunu anlama seviyelerinin yükseltilebilmesi için okumanın bilişsel ve duyuşsal boyutları birlikte düşünülerek gerekli okuma eğitimleri gerçekleştirilmelidir.

\section{Kaynaklar}

Abraham, R. G. ve Vann, R. J. (1987). Strategies of two language learners: a case study. In Wenden, A. L. and J. Rubin (Eds.), Learner strategies in language learning, 85-102, Englewood Cliffs, NJ: Prentice-Hall.

Akkoyunlu, B., Orhan, F. ve Umay, A. (2005). Bilgisayar öğretmenleri için bilgisayar öğretmenliği özyeterlik ölçeği geliştirme çalışması. Hacettepe Üniversitesi Eğitim Fakültesi Dergisi, 29, 1-8.

Altun, F. ve Yazıcı, H. (2011). Ergenlerin benlik algılarının yordayıcıları olarak: akademik öz-yeterlik inancı ve akademik başarı. Kastamonu Eğitim Dergisi, 21/1, 145-156.

Altun, S. ve Aykaç, B. (2009). Lise öğrencilerinin ingilizceye yönelik öz yeterlik algı puanlarının cinsiyete, alanlara ve farklı düzeylere göre ingilizce başarısını yordama gücü. http://www.eab.org.tr/eab/media/kitap/EAB_Kongre_Kitap_2012.pdf. Erişim Tarihi: 11.06.2017.

Altunkaya, H. (2017). İlkokul beşinci sınıf öğrencilerinin okuma kaygıları ile okuduğunu anlama becerileri arasındaki ilişki. International Journal of Language Academiy, 5/3, 106-121.

Bandura, A. (1977). Self-efficacy: Toward a unifying theory of behavioral change. Psychological Review, 84, 191215.

Bandura, A. (1986). Social foundations of thought and action: A social cognitive theory. Englewood Cliffs, NJ: Prentice Hall.

Bandura, A. (1993). Perceived self-efficacy in cognitive development and functioning. Educational Psychologist, $28,117-148$.

Bandura, A. (1997). Self-efficacy: The exercise of control. New York: Freeman.

Bandura, A., Barbaranelli, C., Caprara, G., \& Pastorelli, C. (1996). Multifaceted impact of self-efficacy beliefs on academic functioning. Child Development, 67, 1206-1222.

Bailey, J. M. (2009). Reading poetry for improved adolescent oral fluency, comprehension, and self-perception. Unpublished Master Thesis. Wichita State University.

Baker, L., \& Wigfield, A. (1999). Dimensions of children's motivation for reading and their relations to reading achievement. Reading Research Quarterly, 34, 452-477.

Başaran, S. (2010). Podkestlerin üniversite birinci sınıfta okuyan Türk öğrencilerin dil öğrenme yargıları ve özyeterlik algıları üzerindeki etkileri. Yayımlanmamış Doktora Tezi, Çukurova Üniversitesi Sosyal Bilimler Enstitüsü, Adana.

Baştuğ, M., \& Çelik, T. (2015). Ortaokul öğrencilerinin okur öz algı düzeylerinin cinsiyet, sınıf, okuma ortamı ve sıklığı açısından incelenmesi. International Journal of Human Sciences, 12(1), 903-919. doi: 


\subsection{7/ijhs.v12i1.3120}

Bernhardt, E.B. (1991). Reading development in a second language: Theoretical, empirical and classroom perspectives. Norwood N.J: Ablex.

Bircan, E. ve Uzuner Yurt, S. (2016). Ortaokul öğrencilerinin okuma tutumlari ve okuduğunu anlama öz yeterlikleri arasindaki ilişki. Journal of Academic Studies, 67/17, 201-215.

Carroll, J. M. ve Fox, A. C. (2017). Reading self-efficacy predicts word reading but not comprehension in both girls and boys. Front Psychol. 7:2056. doi: 10.3389/fpsyg.2016.02056.

Chapman, J. W. ve Tunmer, W. E. (1995). Development of young childern's reading self-concepts: An examination of emerging subcomponents and their relationship with reading achievement. Journal of Educational Psychology, 87, 154-167.

Chapman W. J. \& Tunmer E. W. (2003). Reading difficulties, reading- related self-perceptions, and strategies for overcoming negative self- beliefs, Reading\&Writing Quartely, 19, 5-24.

Conway, B. (2017). Reading comprehension and self efficacy. All Capstone Projects. 283. http://opus.govst.edu/capstones/283. Masters of Arts Degree in Multicategorical Special Education Governors State University.

Cortazzi, M., \& Jin, L. (1996). Cultures of learning: Language classrooms in China. In H. Coleman (Ed.), Society and the language classroom (pp. 169-206). Cambridge: Cambridge University Press.

Deci, E. L., Vallerand, R. J. Pelletier, L.G.,ve Ryan, R. M. (1991). Motivation and education: The selfdetermination perspective. Educational Psychologist, 26, 325-346.

Dedebali, N. C. ve Saracaloğlu, A. S. (2010). Hızlı okuma tekniğinin sekizinci sınıf öğrencilerinin okuma hızlarına ve okuduğunu anlama düzeylerine etkisi. Pamukkale Üniversitesi Eğitim Fakültesi Dergisi, 27, 171-183.

Demir, T. (2013). İlköğretim öğrencilerinin yaratıcı yazma becerileri ile yazma özyeterlik algısı ilişkisi üzerine bir çalışma. Uluslararası Türkçe Edebiyat Kültür Eğitim Dergisi, 2/1 84-114.

Erdem, İ., Altunkaya, H. ve Ateş, A. (2017). Türkçeyi yabancı dil olarak öğrenenlerin okur özyeterlikleri ile okuduğunu anlama becerileri arasındaki ilişki. International Journal of Language Academy, 5/4, 74-86.

Epçaçan, C. ve Demirel, Ö. (2011). Okuduğunu anlama öz yeterlik algısı ölçeğinin geçerlik ve güvenirlik çalışması. Uluslararası Sosyal Araştırmalar Dergisi,4(16), 120-128.

Ehrman, M. E. ve Oxford, R. L. (1995). Cognition plus: Correlates of language learning success. Modern Language Journal, 79 (1), 67-89.

Fan, W. \& Williams, C. M. (2010) The effects of parental involvement on students' academic self-efficacy, engagement and intrinsic motivation. Educational Psychology, 30/1, 53-74, DOI: 10.1080/01443410903353302

Guthrie, J. T. \& Wigfield, A. (1999). How motivation fits into a science of reading. Scientific Studies of Reading, 3(3), 119-205.

Guthrie, J. T. \& Wigfield, A. (2000). Engagement and motivation in reading. In M. Kamil, P. B. Mosenthal, P. D. Pearson, \& R. Barr (Eds.), Reading research handbook (Vol. III. ss. 403-424). Mahwah, NJ: Erlbaum.

Güçlü, A. (2009). Sekizinci sınıf öğrencilerinin sınav sırasındaki duygu düzenleme stratejileri: Cinsiyet, bilişsel değerlendirme süreçleri, akademik öz-yeterlik ve sınav kaygısının rolü. Yayımlanmamış Yüksek Lisans Tezi, Ortadoğu Teknik Üniversitesi Sosyal Bilimler Enstitüsü, Ankara.

Graham, S. (1991). A review of attribution theory in achievement contexts. Educational Psychology Review, 3, 5-39.

Hamurcu, H. (2006). Sınıf öğretmeni adaylarının fen öğretimine yönelik öz-yeterlik inançları. Eğitim Araştırmaları, 8, 112-122. 
Henk, W. A., \& Melnick, S. A. (1992). The initial development of a scale to measure perception of self as reader. In C. Kinzer and D. Leu (Eds.), Literacy research, theory, and practice: Views from many perspectives, Forty-first yearbook of the National Reading Conference. Chicago, IL,.111-117.

Henk, W. A., \& Melnick, S. A. (1995). The reader self-perception scale (RSPS): A new tool for measuring how children feel about themselves as readers. The Reading Teacher, 48, 470-482.

Henk, W. A., Marinak, B. A., \& Melnick, S. (2012). Measuring the reader self- perceptions of adolescents: Introducing the rsps2. Journal of Adolescent \& Adult Literacy, 56(4), 311-320.

İnnalı, H. Ö. ve Aydın, S. İ. (2014). İlköğretim 8. sınıf öğrencilerinin okur öz yeterliklerinin çeşitli değişkenlere göre incelenmesi. Turkish Studies, 9(9), 651-682.

Karakoç Öztürk, B. (2015). Ortaokul öğrencilerinin okur öz yeterlikleri üzerine bir araştırma: Adana ili örneği. Adıyaman Üniversitesi Sosyal Bilimler Enstitüsü Dergisi, 21, 908-93.

Karasar, N. (2002). Bilimsel araştırma yöntemi: Kavramlar, ilkeler ve teknikler. Ankara: Nobel Yayıncılık

Keskin, H. K.; Atmaca T. (2014). Okur öz algısı ölçeği-2'nin Türkçeye uyarlanması. İlköğretim Online, 13(1), 306318.

Kubanoğlu, S. (2004). Öz-yeterlik inancı ve bilgi profesyonelleri için önemi. Bilgi Dünyası, 5 (2), 137-152.

Kuşdemir, Y. ve Katrancı, M. (2016). Okumada kaygı ve anlama: Ana fikri bulamıyorum öğretmenim! Eğitim ve Bilim, 41/183, 251-266.

Kuzgun, Y. (2000). Meslek danışmanlığı: Kuramlar; uygulamalar. Ankara: Nobel Yayın Dağıtım.

Kwon, H., \& Linderholm, T. (2014). Effects of self-perception of reading skill on absolute accuracy of metacomprehension judgements. Current Psychology, 33(1), 73-88.

McQuillan, J. (2000). Urban middle- and high-school students' reading attitudes and beliefs: A large-sample survey. Paper presented at the Annual Meeting of the American Educational Research Association, New Orleans, Louisiana.

Pajares, F. (1996). Self-efficacy beliefs in academic settings. Review of Educational Research, 66, 543-578.

Pajares, F. (2002). Gender and perceived self-efficacy in self-regulated learning. Theory in to Practice, 4(2), 116125.

Pajares F. (2003). Self-efficacy beliefs, motivation and achievement in writing: a review of the literature. Reading\&Writing Quartely, 19,139-158.

Phillips, J. (2002). A study of the relationships among grade fours' reader sell-perceptions, reading ability, parental self-efficacy, parental role construction, child development beliefs, and gender. Unpublished Master Thesis, Memorial University of Newfoundland.

Ryan, M.P., ve Pintrich, P. R. (1997). Should I ask for help? The role of motivation and attitudes in adolescents' help seeking in math class. Journal of Educational Psychology, 89, 329-341.

Sallabaş, M. E. (2008). Ilköğretim 8. sınıf öğrencilerinin okumaya yönelik tutumları ve okuduğunu anlama becerileri arasındaki ilişki. Inönü Üniversitesi Eğitim Fakültesi Dergisi, 9(16), 141-155.

Schunk, D. H. (2003). Self-efficacy for reading and writing: Influence of modeling, goal setting, and selfevaluation. Reading \& Writing Quarterly, 19(2), 159-172.

Schunk, D.H. (2008). Learning theories. An Educational Perspective (5thEd.). Pearson Education, Upper Saddle Hill, NJ.

Solheim O. J. (2011). The Impact of reading self-efficacy and task value on reading comprehension scores in different Item formats. Reading Psychology, 32/1, 1-27. http://dx.doi.org/10.1080/02702710903256601

Uçgun, D. (2014). 8. sınıf öğrencilerinin okur öz yeterliklerinin incelenmesi: Niğde ili örneği. International Journal of Language Academy, 2/2, 38-47. 
Ülper, H. (2011). Öğrenci açısından okumaya güdüleyici etmenler. Kuram ve Uygulamada Eğitim Bilimleri Dergisi, 11(2), 941-960.

Ülper, H., Yaylı, D. ve Karakaya, I. (2013). Okur özyeterlik ölçeğinin geliştirilmesi. Ahi Evran Üniversitesi Kırşehir Eğitim Fakültesi Dergisi (KEFAD), 14/1, 85-100.

Walker J. B. (2003). The cultivation of student self efficacy in reading and writing. Reading\&Writing Quartely, $19,173-187$.

Wigfield, A. ve Guthrie, J. T. (1997). Relations of children's motivation for reading to the amount and breadth of their reading. Journal of Educational Psychology Copyright, 89/3, 420-432.

Wigfield, A., Guthrie, J. T., Tonks, S. ve Prencevich, K. C. (2004). Children's motivation for reading domain specificity and Instructional influences. The Journal of Educational Research, 97, 299-309.

Yavuzer, Y. ve Koç, M. (2002). Eğitim fakültesi öğrencilerinin öğretmen yetkinlikleri üzerinde bir değerlendirme. Niğde Üniversitesi Eğitim Fakültesi Dergisi, 1(1), 35-43.

\section{Extended Summary}

In the present study, the research question was set as "Is there a correlation between reader selfefficacy level and reading comprehension skills of 8th grade students." Furthermore, reader self-efficacy level and reading comprehension skills of 8th grade students were investigated in the study. Whether reader selfefficacy level and reading comprehension skills of 8th grade students differed based on gender, parent education level and average monthly income of the family was determined.

Method

This study was conducted with relational screening model, which allows for comparison and correlation-based screening and aims to describe a past or present case in its current state (Karasar, 2002). The study group included 364 students attending 5 junior high schools in the central district of a western province in Turkey. In the study, 'Reader Self-Efficacy Scale' developed by Ülker, Yaylı and Karakaya (2013) and 'Reading Comprehension Academic Achievement Test' developed by Dedebali (2008) were used as data collection instruments and the validity and reliability of these scales were previously determined. In the present study, it was found that the Cronbach's Alpha reliability of the self-efficacy scale was 0.922 . And it was found that the reliability of the reading comprehension form was KR21 $=0.860$ and KR2O $=0.874$. The reliability of both instruments was quite high. The obtained quantitative data were analyzed with SPSS 22 software and the data was expressed with descriptive statistical analysis methods such as count, percentage, mean, standard deviation for assessment. One-way ANOVA test was used to compare the quantitative continuous data between more than two independent groups and the t-test was used to compare the quantitative continuous data between two independent groups. Scheffe test was used as a complementary post-hoc analysis to demonstrate the differences. Pearson's correlation and regression analysis were applied to the continuous variables in the study and the results were assessed at $95 \%$ confidence interval and $5 \%$ significance level.

Results

In the study, the correlation between the reader self-efficacy perceptions and reading comprehension skills of eighth grade students was determined. It was found that as a determinant of the reading comprehension level, the self-efficacy perception decreased the level of reading comprehension. In the study, it was determined that the self-efficacy perception of eighth graders was low with an average score of 1.877. The students' reading comprehension scores were slightly above the average with 72.821 . The reader selfefficacy perception scores of the students were investigated based on the gender variable and it was found that self-efficacy perception scores of female students were lower when compared to the self-efficacy perception scores of the male students. Again, based on the gender variable, the findings on the students' reading comprehension levels revealed that female students were more successful in reading comprehension when compared to male students. In the study, it was found that there was no significant difference between the mean reader self-efficacy perceptions and reading comprehension scores of the students based on education level of the mother. There was no significant difference between reader self-efficacy scores of the students based on father's education level, while there was a significant difference between the reading comprehension scores of the students based on father's education level. Reading comprehension scores of students whose parents were college graduates were higher than those whose fathers were primary, secondary and high school graduates. It was determined that there was no significant difference between reader self-efficacy perceptions and reading comprehension scores of students based on family monthly income variable. 


\section{Discussion and Conclusion}

The self-efficacy belief, which affects human behavior and constitutes the judgments of individuals about whether they can perform a certain task, is one of the factors that affect achievement. Several studies have been conducted on self-efficacy, which was initially suggested as a concept by Bandura. In the said studies, it was determined that students with high reader self-efficacy beliefs were able to acquire the reader skills successfully (Philips, 2002; Schunk, 2003; Walker, 2003; Pajares, 2003; Bailey, 2009; Demir, 2013; Kwan and Linderholm, 2014; Erdem, Altunkaya and Ates, 2017).

In the present study, the correlation between the reader self-efficacy and reading comprehension skills of eighth grade students was determined. It was found that as a determinant of the reading comprehension level, the self-efficacy perception decreased the level of reading comprehension. Demir (2013) investigated the correlation between creative writing skills and writing self-efficacy perceptions of 8th graders, and found that students with high self-efficacy in writing often had good creative writing skills. Solheim (2011) found that self-efficacy had a positive impact on reading comprehension scores of fifth grade students.

In the present study, it was determined that the eighth-grade students had low reader self-efficacy perception levels with an average score of 1.877. Similarly, in a study by Baştuğ and Çelik (2015) titled "The analysis of the reader self-efficacy perception levels of junior high school students based on gender, grade, reading environment and frequency," it was found that the students scored over average points in the development dimension of the scale, scored average points in the observational comparison dimension and scored low points in social feedback and physiological status dimensions.

In the present study, reading comprehension scores of the students were slightly over average with 72.821 points.

The reader self-efficacy scores of the students were investigated in the current study based on the gender variable and the findings demonstrated that the reader self-efficacy perception scores of female students were lower when compared to the reader self-efficacy perception scores of male students.

Analysis of the findings on the students' reading comprehension levels based on the gender variable revealed that female students were more successful in reading comprehension when compared to male students. Arslan (2013) investigated the gender variable in studies on reading skills and stated that certain findings indicated that females were better in certain dimensions such as reading comprehension, some papers, which demonstrated differences based on the gender variable, (could) not explain the reasons for the findings that favored males or females. It was stated that researchers attributed these findings to the feminine nature of reading and the acceptance that females are better in reading when compared to fields such as mathematics and sciences (Piercey, 2013 cited by Karakoç Öztürk, 2015). The results of different studies (Gündemir, 2002; Sallabaş, 2008; Karatay, 2010; Köseoğlu, 2011; Ünal, 2012; Altunkaya, 2017) revealed that female students were more successful, consistent with the findings of the present study.

In the present study, it was found that there was no significant difference between students' reader self-efficacy perceptions and reading comprehension mean scores based on education level of the mother. In the study, there was no significant difference between reader self-efficacy perceptions of the students based on father's education level, while there was a significant difference between reading comprehension scores. Reading comprehension scores of students whose parents were college graduates were higher than those whose fathers were primary, secondary and high school graduates. Kuşdemir and Katrancl (2016) found that students' reading comprehension levels improved as the parents' education level increased from primary school to college level. In a study conducted with fifth grade students by Altunkaya (2017), it was found that the achievement scores of elementary and high school students, whose mothers were primary or high school graduates, were higher than those with non-literate mothers, the achievement scores of the students, whose fathers were primary and high school graduates, were higher than those with non-literate fathers and the achievement scores of the students, whose fathers were high school graduates were higher than those whose fathers were college graduates.

It has been determined that there was no significant difference between reader self-efficacy perceptions and reading comprehension scores of students based on family monthly income. Bircan and Uzuner Yurt (2016) investigated the correlation between reading attitudes and reading comprehension selfefficacy of junior high school students and found that self-efficacy perceptions decreased as students' economic conditions worsened. 